\title{
The Keith/Albee Collection: The Vaudeville Industry, 1894-1935.
}

\section{ALISON KIBLER}

\section{In the late 1880s, Benjamin Franklin}

Keith and Edward F. Albee, acquaintances from their earlier days in the circus business, joined forces to promote "polite" vaudeville. To this end, Keith and Albee opened several lavishly remodeled theatres on the east coast, censored most crude remarks and revealing costumes from performances at their theatres and prohibited boisterous behavior such as hissing at performers during their productions. The Keith and Albee brand of "high class" vaudeville was thus underway by the end of the nineteenth century. ${ }^{1}$ The Keith/Albee Collection at The University of Iowa Special Collections Department preserves much of the cultural and industrial history of this vaudeville circuit. Though information about Iowa is scarce in the Keith/Albee Collection, The University of Iowa has nevertheless been the location of this important resource for vaudeville historians since 1976 . While the collection focuses mainly on vaudeville in Rhode Island between 1894 and 1935, it is also a valuable resource for vaudeville throughout the east coast and in parts of the Midwest, mainly Ohio. The Keith/Albee collection has already played a prominent role in the interpretation of vaudeville history: Robert C. Allen relies on this collection in his 1980 study, Vaudeville and Film 1895-1915: A Study in Media Interaction, and Robert W. Snyder draws on the

${ }^{1}$ Clipping Book 1903-1904, p. 9, Keith/Albee Collection, Special Collections Department, University of Iowa. 
Keith/Albee records in his recent history of vaudeville, The Voice of the City: Vaudeville and Popular Culture in New York (1989). ${ }^{2}$ The varied sources in the Keith/Albee Collection should continue to influence scholars' accounts of turn-of-thecentury entertainment.

The Keith/Albee Collection chronicles the expansion of the circuit, changes in leadership and the decline of vaudeville. Through the establishment of a central booking office (the United Booking Office) in 1906, Keith and Albee extended their power in vaudeville. Every act that sought employment at any of the member theatres had to work through this office, paying the United Booking Office five percent commission for the service. While Keith was financial head of the circuit, Albee was the general manager and also owner of several theatres. After Keith's death in 1914, his son A. Paul Keith replaced him. Albee gained control of the Keith/Albee circuit following A. Paul Keith's death in 1918. In the mid-1920s vaudeville's popularity began to ebb as the success of motion pictures increased. Albee first tried to stem the decline of "high-class" vaudeville by merging with a prominent western chain of vaudeville theatres, the Orpheum Circuit, forming the KeithAlbee-Orpheum Circuit in 1927, but in 1928 he sold \$4,500,000 worth of stock to film magnate Joseph P. Kennedy. ${ }^{3}$ After Keith-Albee-Orpheum combined with Kennedy's Radio Corporation of America (RCA) to establish Radio-Keith-Orpheum (RKO), Albee lost his control over the organization and films became the primary entertainment, although vaudeville survived as an accompaniment to feature films through the mid-1930s.

${ }^{2}$ Robert C. Allen, Vaudeville and Film, 1895-1925: A Study in Media Interaction (New York: Arno Press, 1980). This book is a revision of his Ph. D. dissertation at The University of Iowa in 1977. Robert W. Snyder, The Voice of the City: Vaudeville and Popular Culture in New York (New York: Oxford University Press, 1989). M. Alison Kibler's dissertation, "The Keith Vaudeville Circuit, 1890-1920: Gender, Sexuality and the Cultural Hierarchy," also draws heavily on this collection.

${ }^{3}$ Untitled article, May 19, 1928, Clipping Book, December 5, 1927 to May 28, 1928, page 240. Keith/Albee Collection. 


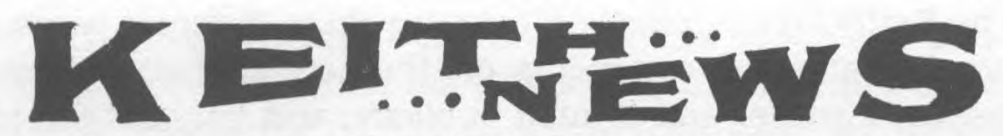

THE OXLY DRAMATIC PAPER PUBLISHED IN RHODE ISLAND.

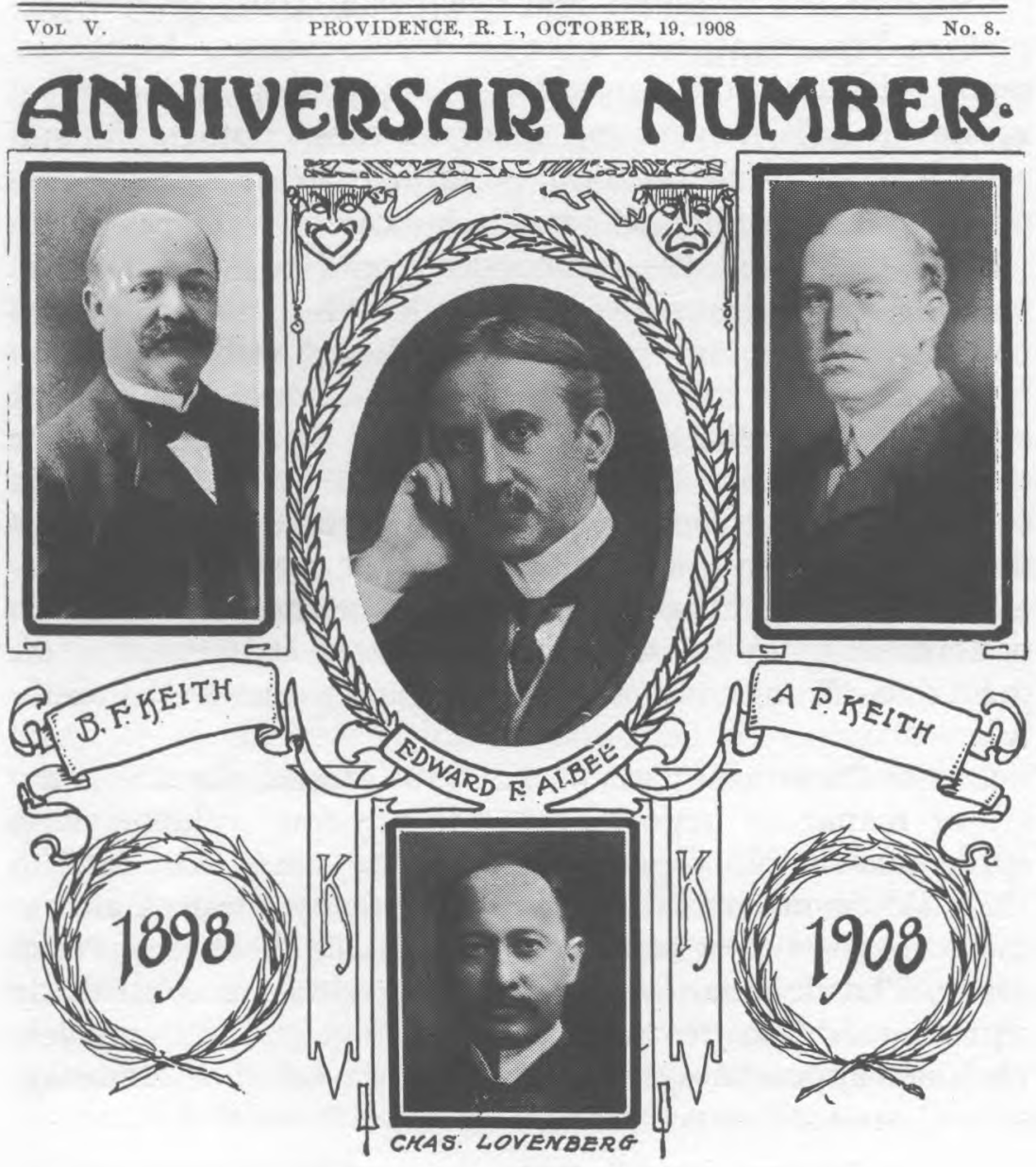

This October 19, 1908 cover of Keith News features the four businessmen responsible for the success of Keith vaudeville in Providence. 
The Keith/Albee Collection contains three different types of sources: managers' comments on the acts at their theatres, newspaper articles and printed publicity, and financial records for theatres in Providence and Pawtucket. These sources emphasize different aspects of the vaudeville industry. Managers' reports discuss the organization and popularity of individual vaudeville bills; advertising often features photographs and sensational information about performers to attract more customers; and the financial records indicate how managers rewarded their employees economically and how the theatres' profits fluctuated from week to week. While the volumes of newspaper clipppings - the "clipping books" - for Providence cover the years from 1894 to 1935, the managers' "report books" begin in 1902 and end in 1923 and the financial records cover approximately 1900 to 1929 . Thus the information in this collection is most comprehensive for the first two decades of the twentieth century. Vaudeville theatre managers, treasurers, and press agents generated most of this material. Although performers are central to this collection, researchers encounter them only through the records of administrators on the Keith/ Albee circuit.

One of the largest parts of the Keith/Albee Collection is the set of managers' report books; twenty-four volumes with approximately 225 pages each cover the years from 1902 to 1923. While managers' reviews from many theatres are included in the report books, only vaudeville theatres in Providence, Philadelphia, Boston, and Cleveland are consistently represented. ${ }^{4}$ Theatres in Detroit, Washington, D.C., and New York also appear fairly regularly. ${ }^{5}$ Every week theatre manag-

${ }^{4}$ The Providence vaudeville theatre, the central theatre in this collection, underwent several name changes. B.F. Keith's Opera House opened in 1894 with Albee as general manager and John T. Fynes as resident manager. The B.F. Keith's Opera House was renamed Keith's New Theatre from 1900-19, the E.F. Albee Theatre from 1919 to 1929, and the RKO Albee Theatre from 1929 to 1935.

${ }^{5}$ Theatres that appear intermittently in the report books include: Castro Theatre in Fall River, Massachusetts; Hyde and Behman's in Brooklyn, New York; Grand Opera House in Pittsburgh, Pennsylvania; Shea's Theatre in Buffalo, New York; Keith's Theatre in Baltimore, Maryland; Harlem Opera House in Harlem, New York; the Colonial Theatre in Lawrence, Massachusetts; a theatre in Columbus, Ohio; Bijou 
ers on the Keith/Albee circuit sent a review of the acts playing at their theatres to other managers on the circuit as part of an effort to control the quality of acts and circulate advice about where to position acts on a bill. ${ }^{6}$ Managers wrote a brief analysis of each act; the length of the comments varies depending on the managers' approach to the reviews and on the type of act. While H. Winnifred DeWitt, manager of Chase's Theatre in Washington, D.C., rarely wrote more than two sentences about a performer, Charles Lovenberg and Carl Lothrop, managers of Providence and Boston theatres respectively, often wrote four to six sentences. In addition, managers' reports regularly include the following: the order of acts, the number of minutes an act spent on stage, a designation of whether an act used the full stage or only the front part of the stage (using the front section of the stage was called performing in "one"), an indication of whether the act performed two or three shows a day, and an assessment of the overall quality of the bill. Furthermore, some theatre managers listed their cuts - the parts of an act that a manager forced performers to eliminate because he or she found it offensive. These books, therefore, yield extensive information about the organization of vaudeville bills as well as managers' regulation and evaluation of the acts.

Some historians have noted the difficulty of researching vaudeville without extensive visual or written records of acts as they appeared on stage. Managers' reports offer some clues here. With some singers, for example, managers listed the titles of the songs they sang. The manager of Keith's theatre in Philadelphia noted that opera singer Madame Slappoffski "performed 'Jewel Song' from Faust, 'Scenes That are Bright-

Theatre in Pawtucket, Rhode Island; the Bijou in Woonsocket, Rhode Island; the Hudson Theatre in Union Hill, New Jersey; B.F. Keith's Columbia Theatre in Cincinnati, Ohio; and Trent Theatre, Trent, New Jersey.

${ }^{6}$ The number of acts on a bill varied over the years. Before 1919, the Providence theatre featured fourteen or fifteen acts on a bill, but after 1908, the bills became shorter, including only eight to ten acts. This change is a result of the theatres' termination of its continuous performance policy-in which live vaudeville acts appeared on stage from ten in the morning to ten at night. After March 29, 1909, three hour shows began at 1:45 and 7:30. 
est' from Maritana and Tosti's 'Goodbye'."7 Managers also offered plot summaries of playlets. A New York manager described the plot of a comedy sketch, "Shipmates", in 1904:

It takes place on the deck of an old stranded schooner at New Bedford, the boat being occupied by two superannuated captains who have signed articles to the effect that no female shall ever come on board. A widow dies, leaving in the charge of one of them a little girl supposed to be about fourteen years of age. One of them wants to take her on the boat, and the other absolutely objects until the finish...it can be considered a very good sketch. ${ }^{8}$

Along with listing song titles and describing the plots of dramatic sketches, managers often commented on elaborate scenery. Carl Lothrop, for example, remarked that Annette Kellermann's "exhibition of fancy diving [required] a special tank, seven feet deep with a capacity of 25,000 gallons of water." In addition, managers often devoted more time to an act's first appearance on the Keith circuit than to an act's return engagement. Overall, managers' report books do not consistently offer detailed descriptions of vaudeville acts, however. While researchers, for example, can learn that Lovenberg felt that trapezist Valesca had a "very nice personality" we do not learn what tricks she performed, in what sequence she performed them, or what she wore on stage. ${ }^{10}$ Managers offered their colleagues an impression of the act, not an extensive chronology of the sights and sounds of each performance.

Managers' reports often include insights into the characteristics of vaudeville audiences. With ticket prices as low as fifteen cents at Keith's in Providence in 1903, vaudeville was affordable to a wider range of patrons than "high culture" like legitimate drama at the turn-of-the-century. ${ }^{11}$ The September 21, 1903 program for Keith's in Providence indicates the

${ }^{7}$ Report Book 2, page 112, Keith/Albee Collection. Not surprisingly, Slappoffski appears to have been a stage name; one manager listed this performer's last name as "Neilson". Report Book 3, page 22, Keith/Albee Collection.

${ }^{8}$ Report Book 1, page 155, Keith/Albee Collection.

${ }^{9}$ Report Book 8, page 177, Keith/Albee Collection.

${ }^{10}$ Report Book 1, page 88, Keith/Albee Collection.

${ }^{11}$ Robert C. Allen, Horrible Prettiness: Burlesque and American Culture (Chapel Hill: University of North Carolina Press, 1991): 186. 
following prices for a matinee: orchestra, all reserved, thirtyfive cents; first balcony, all reserved, twenty-five cents; and second balcony, admission fifteen cents. Discussing how acts appealed to different segments of the audience, managers frequently revealed the problems of catering to an eclectic audience. In Detroit in 1904, a manager commented that the Vilona Sisters, a group of violinists, "went very well here particularly with the box people and the more cultured of the downstairs generally." 12

According to managers' accounts, the theatre audience was divided by gender as well as class. One manager wrote that Sophye Bernard's costume captured the interest of female patrons: "One of her gowns is worn without corsets and has created no end of criticism, being noticed more particularly by the women."13 In 1903 John Healy, according to one manager on the Keith/Albee circuit, "always seems to be especially funny to the ladies of the audience, and as our matinees are largely composed of females he simply had them his own way."14

By studying managers' report books, historians can uncover the standards by which managers measured vaudeville acts. The pressure to maintain "respectability" on the Keith/Albee circuit was one of managers' central concerns. From managers' records of the changes they made to various acts, researchers can learn about their sense of propriety. Managers asked bare-legged women to put on tights and ordered female performers to lengthen their skirts and discontinue high kicks. They also eliminated many phrases from performers' repertoires: From comedian Chris Richard's 1918 act, Lovenberg cut "what the devil," "damn," and "son of a gun."15 If taming suggestive acts was one of managers' tasks, the search for novelty was another. Managers expressed little enthusiasm for veteran vaudevillians who had not revised their acts from the

\footnotetext{
${ }^{12}$ Report Book 1, page 185, Keith/Albee Collection.

${ }^{13}$ Report Book 14, page 32, Keith/Albee Collection.

${ }^{14}$ Report Book 1, page 19, Keith/Albee Collection.

${ }^{15}$ Report Book 20, page 117, Keith/Albee Collection.
} 
previous season and they praised unusual acts, including women performing traditional male acts. Two acrobats, Tony Wilson and Mademoiselle Heloise, earned Boston manager M.J. Keating's approval: "Another great 'sight' act, which scored a hit. The novelty in it is the woman doing the work usually performed by the male partner and doing it well."16

The collection of Keith/Albee report books may be an important starting point for scholars who are studying managers in the vaudeville industry. The report books provide the names of over twenty-five managers of theatres from cities in the East as well as the Midwest and often cover the beginning and end of a manager's employment at a theatre (See Appendix for a partial list of managers). A small amount of information about Providence managers' education, professional and family backgrounds is included in the newspaper articles saved in the "clipping books" of the Keith/Albee Collection. For example, in an article discussing the opening of B.F. Keith's Opera House in 1894, the author reveals that the theatre manager, John $T$. Fynes was formerly involved in the newspaper business with the Evening World, of New York and that his brother, J. Austin Fynes, was the manager of Keith's Union Square Theatre in New York. An article about the opening of a new vaudeville theatre in Pawtucket, Rhode Island, in October 1903 reveals that Charles Lovenberg, a native of New Orleans, became the manager of Keith's theatre in Providence several years after he worked as the musical director of Keith's theatre. ${ }^{17}$ Information about the backgrounds of non-Providence managers is not available in the Keith/Albee records, however.

The report books reveal that men dominated the ranks of Keith/Albee managers: H. Winnifred DeWitt, manager of a Washington, D.C., theatre, is the only female manager to appear in the report books. Two other female administrators emerge in the Keith/Albee Collection. Clara Blaney, an actress in the Edward F. Albee Stock Company in 1901, became

\footnotetext{
${ }^{16}$ Report Book 1, page 6, Keith/Albee Collection.

${ }^{17}$ Untitled article from the Pawtucket Evening Times, 13 October 1903. Clipping Book 1903-1904, p. 43. Keith/Albee Collection.
} 
Lovenberg's press agent for the Providence theatre and for his production of several vaudeville acts-the Tuscany Troubadours, La Petite Revue, the Operatic Festival, and College Life (a musical comedy production). Laura F. Albee served as the Vice president of the Providence Theatre Company under President Edward F. Albee. Although the Keith/Albee collection does not offer extensive information about these women's backgrounds, it does include a glimpse of the long-overlooked role of women in managing and promoting vaudeville.

While the Keith/Albee report books present managers' perspectives, they can also offer insights into performers' acts and careers. Featuring descriptions of little-known performers as well as prominent vaudeville stars, the report books are an important resource for vaudeville historians who want to recover the rank-and-file performers, not only the elite players. Marginal or mediocre vaudevillians usually receive more attention than stars in the reports because stars' acts were so well-known, managers saw little need to recount their performances for other managers. In 1909 Carl Lothrop, manager of Keith's Theatre in Boston, wrote of Eva Tanguay, simply, "Just Tanguay, that's all."18 Prominent performer Zelda Sears warranted only the following quip in 1912: "Another act that everybody knows about."19 Despite the frequently brief discussion of stars, the Keith/Albee Collection may be some help for scholars writing biographies of stars or focusing on a few renowned performers. The series of report books can, for example, provide a glimpse of performers before they became famous. In 1903, several years before she became a top vaudeville performer, Nora Bayes "surprised" Lovenberg with her "magnetic personality."20 Unfortunately, only the first four report books (1902-1905) are indexed; handwritten listings appear in the front of these books. The report books thus do not lend themselves well to tracking a few individuals, unless

\footnotetext{
${ }^{18}$ Untitled article from the Pawtucket Evening Times, 13 October 1903. Clipping Book 1903-1904, p. 43. Keith/Albee Collection.

${ }^{19}$ Report Book 14, page xii, Keith/Albee Collection

${ }^{20}$ Report Book 1, page 61, Keith/Albee Collection.
} 


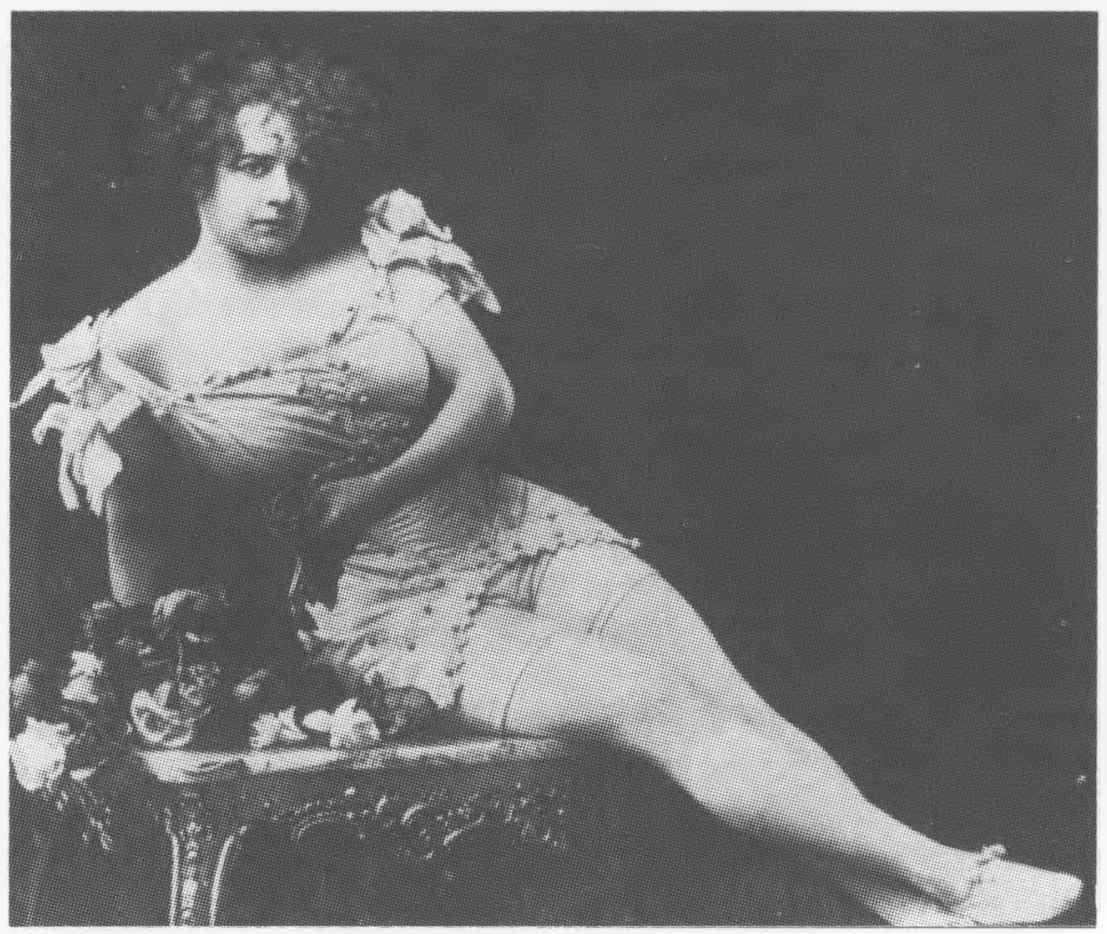

Tanguay, one of the most famous vaudeville stars, appeared in Providence during the week of January 6, 1908.

the researcher knows the dates and locations of the vaudevillians' appearances on the circuit.

As Nora Bayes' case shows, these report books often illuminate the changes in performers' status on the Keith/Albee circuit in successive seasons. Managers frequently commented on performers' poor choice of music and dramatic material, and they also acknowledged performers' successful revisions. In 1918 Lovenberg noted that Juliette "has improved her work materially and the act is better because of the lack of change of costumes formerly made. "21 Changes in vaudeville's status and the popularity of certain types of acts also determined a performer's fate as Lovenberg reveals in his explanation of the

${ }^{21}$ Report Book 20, page 108, Keith/Albee Collection. 
waning popularity of juggler Selma Braatz in 1917: "It is quite complimentary to the progress of vaudeville to realize that this young woman, a few years ago, was a headliner and while doing fully as good an act and probably a little better one than she did then, is now opening our show, and while satisfactory in that position, is not a remarkable good opening act." 22 By reading managers' reports, researchers can gain insight into the events influencing performers' success on the Keith/Albee circuit.

The report books also provide information about the conditions under which performers worked on the Keith/Albee circuit. Travel was frequently a problem for performers: managers often wrote about performers arriving late or with little time to spare, often without their luggage. Suggesting the hectic, uncertain lives of performers, Foster Lardner remarked that Madeline Collins "just made the show after a long jump from Syracuse." 23 Managers' comments reveal performers' discontent with the Keith/Albee system as well. M. J. Keating recorded Jessie Couthoui's protest in his report for 1909: "Jessie Couthoui, not satisfied with her time on the evening bill, refused to go on, which is direct benefit to the program." 24 Thus,although reports were written by and for Keith/Albee managers, they can still highlight players' struggles on the circuit.

The information in report books can also give historians insight into the different treatment of women and minorities in the vaudeville labor force. Managers' remarks about female performers almost always emphasize beauty and appearance: classical singers' exhibition of gowns was important to managers, as were female performers' figures. Carl Lothrop remarked that Katherine Bloodgood was "one of the handsomest women in the varieties, stunningly gowned." 25 Some managers believed that certain types of performances-such as classical

\footnotetext{
${ }^{22}$ Report Book 19, page 159, Keith/Albee Collection.

${ }^{23}$ Report Book 23, page 120, Keith/Albee Collection.

${ }^{24}$ Report Book 2, page 10, Keith/Albee Collection

${ }^{25}$ Report Book 2, page 18, Keith/Albee Collection
} 
singing - were inappropriate for African-American women and they often criticized African-American performers for trying to hide the color of their skin. M. J. Keating, manager of a Boston Theatre felt that Margaret Scott made "up to look white and succeeds in being ghastly through the excessive use of powder on her sallow skin." 26 The report books give scholars a glimpse of some of the problems women, particularly African-American women, encountered on the Keith/Albee circuit.

Along with documenting the managers' evaluation of vaudeville programs and performers' struggles on the Keith/Albee circuit, the twenty-four volumes of managers' reports provide information about the integration of motion pictures into vaudeville bills. Robert Allen, in Vaudeville and Film, 1895-1915: A Study in Media Interaction, uses the Keith/Albee Collection to analyze the reception of early motion pictures and the changing status of motion pictures on vaudeville bills. Managers' reports include the titles of films, their success with audiences, and the technical problems associated with projection. Arguing against the notion that films, because of their unpopularity, were used to chase patrons out of the vaudeville theatres, Allen, drawing on managers' comments, asserts that films were not always last on the programs and that they were, in fact, quite popular. As Allen's research demonstrates, the report books in the Keith/ Albee Collection provide clues about the changes in film topics as well as audience responses.

The Keith/Albee collection preserves another important component of this vaudeville industry-advertising. Report books frequently present managers' strategies for promoting acts. Carl Lothrop, for example, explained his strategy for promoting La Sylphe, a dancer who was famous for performing the erotic dance, "Salome": "We made no mention, whatsoever, of 'Salome' in connection with her advertising or billing, announcing her as a classic dancer. I do not think that anybody

\footnotetext{
${ }^{26}$ Report Book 3, page 27 . In addition, Lovenberg wrote of singer Rosa Lee Tyler: "Her voice is metallic and screechy and her make-up is decidedly bad as she powders up considerably in order to disguise the fact that she is a Negro, but I shall endeavor to have her discontinue." Report Book 1, page 127, Keith/Albee Collection.
} 
can take offense at this act. If they do they must be unreasonably prudish." 27 Most information about publicity, however, is located in other parts of the Keith/Albee collection - the "clipping books" and the book of "caricatures".

The clipping books include all of the publicity for Keith's vaudeville and the Edward F. Albee Stock Company in Providence, Rhode Island, a dramatic company that presented plays during the summer months (April to August) from 1901 to 1929. The first clipping book starts with the opening of Keith's Opera House in Providence on September 10, 1894; the last covers the RKO Albee Theatre's presentation of feature films and five or six vaudeville acts in 1935. The person who compiled these clipping books - perhaps Charles Lovenberg or Clara Blaney-saved the publicity about Providence vaudeville from area newspapers. Articles from the Providence Journal, the Rhode Island Pendulum, the Pawtucket Evening Times, the Olneyville Times, the Providence Unzeiger, and others are part of the clipping books. Most of the articles about any single bill at Keith's are nearly identical because they follow the theatre's press releases closely. Reviews by critics unaffiliated with the theatre are not included.

The articles and advertisements clarify the hierarchy of the vaudeville bills in Providence. In promotional articles a short paragraph is usually devoted to the headline act, while acts lower on the bill receive only a sentence; the stars of the bill receive the largest print in the advertisements. The Providence vaudeville theatre became more creative over the years in expressing the arrangement of the bill, moving from simple listing of the titles of acts in block letters of varying size to elaborate illustrations. In December 1907, for example, Keith's theatre depicted the attractions of their bill in a cartoon featuring Santa Claus unloading gifts from his bag in front of a fireplace. The name of the premiere act on the bill-a musical

${ }^{27}$ Report Book 8, page 161. Keith/Albee Collection. Richard Strauss' opera Salome incited public outrage when it first appeared at the Metropolitan Opera on January 22, 1907 largely because of the eroticism of the dancer's shedding of seven veils. 
comedy "The Songbirds" - appears in large letters on Santa's bag. The middle-level acts are listed on long stockings hung on the mantel, while the least significant acts are relegated to the smallest stockings. ${ }^{28}$ When the rank of acts in the Providence theatre is not clear from managers' reports, "clipping books" can be an important guide to the organization of the bill.

The "clipping books" for Providence also contain a long series of Keith News, the promotional newsletter for Keith's in Providence. Keith News features a photograph of the upcoming headliner on the cover, an article about this performer, as well as a regular column by "The Lady Behind the Pen." "The Lady Behind the Pen" addresses a variety of topics - from tips on proper etiquette for audience members to instructions for evacuating the theatre in case of fire. In addition, the "clipping books" contain many articles about controversies surrounding Keith's Theatre in Providence. In April 1907, for example, several articles recorded the debates about a Rhode Island bill aimed at preventing the attendance of juveniles unaccompanied by adults at theatres.

Other collections of newspaper clippings in the Keith/Albee Collection move beyond Providence, Rhode Island. Nine volumes of clipping books cover the vaudeville theatre in Pawtucket and one oversize book titled "Caricatures" contains a variety of vaudeville publicity from other cities on the KeithAlbee-Orpheum Circuit: caricatures or cartoons by "Tracy", newspaper articles about vaudeville stars, and clippings from various theatres' promotional newsletters (The Hudson Theatre News, The B.F. Keith Theatre News, and The Orpheum News). The caricatures, usually undated, depict artists performing in Oakland, California; Bridgeport, Connecticut; and Washington, D.C., among other locations. Often quite humorous, the caricatures offer insight into performers' personas and appearances.

\footnotetext{
${ }^{28}$ Untitled advertisements, Clipping Book November 1907- April 1908, page 40, Keith/Albee Collection.
} 


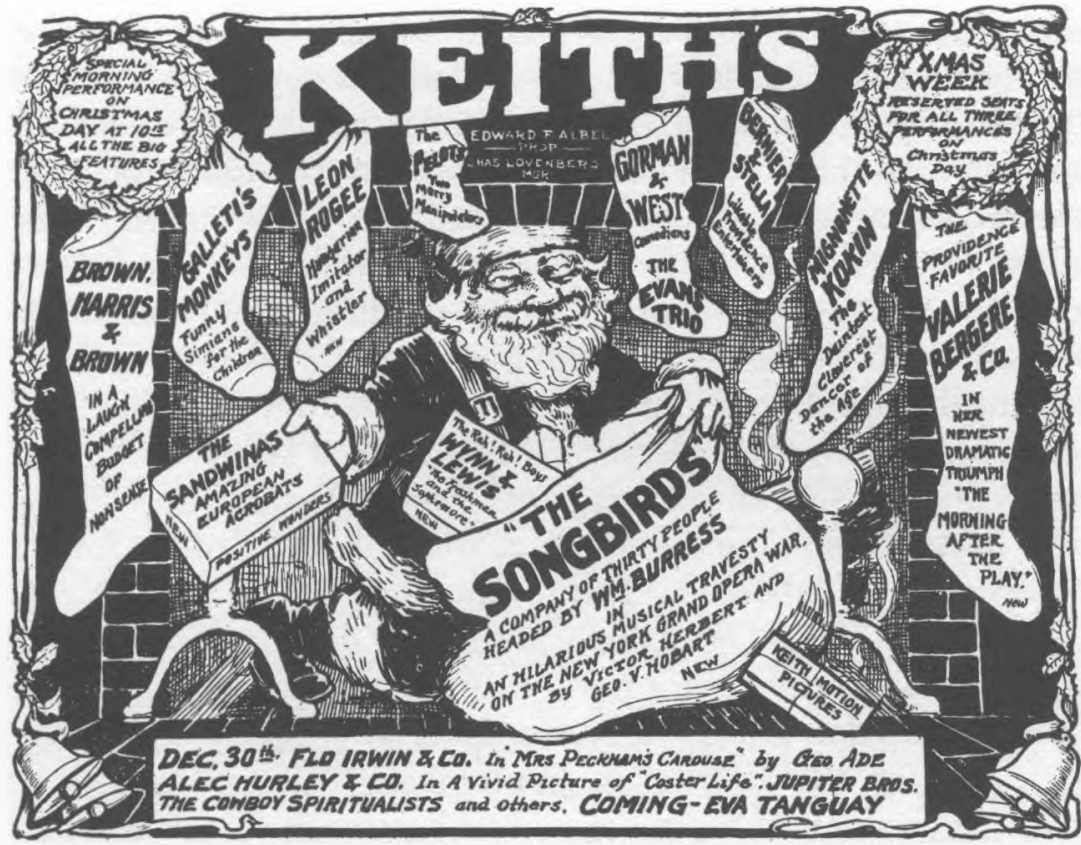

This advertisement for Keith's Theatre appeared in Providence area newspapers on December 22, 1907.

The Keith/Albee collection also includes five volumes of reviews of "New Acts" from Variety and the New York Clipper, two trade newspapers. These reviews are more detailed than those provided by vaudeville managers in the report books but they are difficult to use because they are undated and describe acts from various parts of the country. Therefore, although a researcher may happen to match a helpful description of a performer in "New Acts" with a manager's evaluation in the report books, there is no fast way to locate performers in the five volumes of "New Acts."

Along with managing Keith's Theatre in Providence, Charles Lovenberg produced many vaudeville acts. Four scrapbooks of clippings document four of Lovenberg's acts: the Tuscany Troubadours, La Petite Revue, the Operatic Festival, and College Life. Each scrapbook follows one of Lovenberg's acts for one or two years, including the press releases and photographs 
from their tours. The Tuscany Troubadours was an operatic sextet comprised of Mary Madison, Mabel Rettew, Elsa Van der Voort, John O'Donnell, Albert Wallerstaedt, and Edward Larivierre. Publicity for this act, written by Clara Blaney, stressed its artistic nature. Mary Madison, for example, was linked to an Italian opera instructor, Vannuccini. The scrapbook for La Petite Revue, a group of three men and three women, follows the group from September 1908 to May 1910 and includes publicity, again written by Blaney. Lovenberg's next production, the Operatic Festival, was a larger undertaking. Featuring sixteen soloists, the Operatic Festival appears to have been an expanded version of the Tuscany Troubadours. The fourth Lovenberg production included in the Keith/Albee Collection is College Life, a musical comedy drawing on a cast of eighteen to twenty performers, including Minerva Courtney, Elphye Snowden and Fred Newcombe. The College Life scrapbook follows the tour from September 1910 to May 1911. Lovenberg is one of the most pivotal figures in this collection. His administration of Keith's Theatre in Providence and promotion of his own acts are central activities preserved in the Keith/Albee Collection.

The Keith/Albee collection contains several volumes of "Bookings" for the vaudeville theatre in Providence, from 1900 to 1911. Much of the information in the "Bookings" overlaps with the managers' report books: both include the time acts spent on stage, the type of act, the use of the stage-full or in one-and the number of shows per day. These booking records are important, however, because they include salary information that most of the managers' reviews in the report books omit. The salaries are, unfortunately, indicated in an industrial code. The only information about salaries in the Keith/Albee Collection that are written in dollar amounts is a folder of salary information for vaudeville performers at the Bijou Theatre in Woonsocket, Rhode Island, from 1920-1922.

Treasurer's Statements for the E.F. Albee Theatre offer some information on the weekly expenses of a theatre from May 1919 to January 1920. On November 15, 1919, the treasurer, Loven- 
berg, noted a long list of general expenses, including imitation leather for seats $(\$ 120)$, laundering the ushers' collars, cuffs and aprons $(\$ 10)$, and a typewriter $(\$ 70)$. Also, in the treasurer's documentation of expenses, he includes the total salary of vaudeville or stock payroll as well as the total of the house payroll. For the week of November 15, 1919, the total of the house salaries was $\$ 1,426.68$, while the vaudeville salaries totalled $\$ 3,725.00 .{ }^{29}$ Scholars interested in the fluctuating costs of the maintenance of a vaudeville theatre, including the costs of vaudeville bills, may find this information useful.

Following the peak of vaudeville's popularity as well as its decline, the Keith/Albee Collection captures a period of transformation in the history of commercial entertainment in the United States. Conflicts between managers and performers, the consolidation and expansion of Keith/Albee vaudeville in the early twentieth century, as well as the evolution of the promotion of vaudeville acts in Rhode Island are all themes of the Keith/Albee Collection. Scholars interested in the Keith/ Albee industry and performers on the Keith/Albee circuit will find that the Collection is well worth a trip to Iowa City.

${ }^{29}$ Treasurer's Statement Book, E. F. Albee Theatre, Keith/Albee Collection. 


\section{Appendix: Partial List of Theatre Managers}

John F. Adams

C.E. Barnes

David R. Buffington

J. F. Clancy

H. Winnifred DeWitt

C. L. Doran

L. M. Eirick

J. H. Finn

John T. Fyne

John P. Harris

Ned Hastings

Samuel Hodgdon

Robert E. Irwin

M. J. Keating

J. J. Keirnans

R. G. Larsen

Charles Lovenberg

E. P. Lyons

M. Moses

John C. Peebles

W. W. Prosser

E. F. Rogers

Frederick Schanberger

H. K. Schokey

Joseph R. Smith

Al Staynes
Lawrence, Massachusetts

Philadelphia, Pennsylvania

Pawtucket, Rhode Island

Trent, New Jersey

Washington, D.C.

Cincinnati, Ohio

Cleveland, Ohio

Detroit, Michigan

Providence, Rhode Island

Pittsburgh, Pennsylvania

Cleveland, Ohio

New York, New York

New York, New York

Boston, Massachusetts

Philadelphia, Pennsylvania

Boston, Massachusetts

Providence, Rhode Island

Philadelphia, Pennsylvania

Trent, New Jersey

Union Hill, New Jersey

Colombus, Ohio

New York, New York

Baltimore, Maryland

Cincinnati, Ohio

Union Hill, New Jersey

Fall River, Massachusetts 